\title{
Assessment of Serum and Salivary Progranulin Levels in Oral Submucous Fibrosis
}

\author{
Swarnalakshmi $\mathbf{R}^{1^{\star}}$, Ramya $\mathbf{R}^{1}$, Priyadharshini $\mathbf{N}^{1}$, Preethi $\mathbf{L}^{1}$, Rajashree $\mathbf{P}^{2}$ and Rajkumar ${ }^{1}$ \\ ${ }^{1}$ Department of Oral Pathology, SRM Dental College, Chennai, India \\ ${ }^{2}$ NCNST, University of Madras, Chennai, India
}

"Corresponding author: Swarnalakshmi R, Department of Oral Pathology, SRM Dental College, Chennai, India, Tel: 9840019504, E-mail: dr.swarna1oralpath@gmail.com

Received date: February 20, 2018; Accepted date: March 03, 2018; Published date: March 10, 2018

Copyright: (C2018 Swarnalakshmi R, et al. This is an open-access article distributed under the terms of the Creative Commons Attribution License, which permits unrestricted use, distribution, and reproduction in any medium, provided the original author and source are credited.

\begin{abstract}
Background: Oral submucous fibrosis is a chronic inflammatory condition and a common potentially malignant oral disorder. It has been postulated that inflammation and cancer share a common link by activation of common transcription factors which enhances gene expression involved in the regulation and production of inflammatory mediators and also in the regulation of survival and proliferation of cancer cells. Inflammation has been added as one of the hallmarks in cancer development. Progranulin or proepithelin is a high molecular weight secreted mitogen, it has been recently introduced as a novel marker for chronic inflammatory response. The functions of progranulin is multifaceted; progranulin levels have yet been unexplored in the context of submucous fibrosis as well as oral cancer.
\end{abstract}

\section{Aim: To assess Serum and Salivary Progranulin Levels in Oral Submucous Fibrosis.}

Materials and methods: The study consisted of two groups. Group I (Control N=10) and Group II (OSMF N=30). Serum and salivary samples were collected and further progranulin levels were analysed using ELISA.

Results: Overall, the results of the present study showed that the levels of progranulin were elevated both in serum and saliva of patients with OSMF The serum progranulin levels correlated positively with salivary levels $(p<0.001)$. In addition the progranulin levels increased significantly as the stages of OSMF progressed.

Discussion: Amongst the various inflammatory mediators, TNF- is one of the key mediators which play a vital role in the pathogenesis of OSMF. Progranulin, the novel ligand of TNFR1/2 receptors could be one of the reasons for causing decrease in collagenase enzyme and increase in collagen production with progression of disease severity. Hence it can be inferred that this multifaceted molecule, progranulin has an important role to play in the pathogenesis of OSMF.

Conclusion: Progranulin, the novel ligand of TNFR1/2 receptors could be one of the reasons for causing decrease in collagenase enzyme and increase in collagen production with progression of disease severity. Hence it can be inferred that progranulin has an important role to play in the pathogenesis of OSMF.

Keywords: Progranulin; Oral submucous fibrosis; Precancerous; Elisa; Saliva

\section{Introduction}

Oral submucous fibrosis (OSMF) a potentially malignant disease was first described in 1950s [1]. OSMF is characterized by inflammation leading to progressive fibrosis of lamina propria and deeper connective tissues, followed by stiffening of an otherwise yielding mucosa resulting in difficulty of mouth opening [2].

Worldwide the estimate of OSMF seems to be restrained to Southeast Asia. The overall prevalence rate in India is about $0.2 \%$ to 0.5 $\%$. Prevalence by gender varies from $0.2-2.3 \%$ in male and $1.2-4.57 \%$ in female [3]. The morbidity rate is high in OSMF because there is progressive inability to open the mouth which results in difficulty in eating and consequent nutritional deficiencies. OSMF has one of the highest rates of malignant transformation into oral squamous cell carcinoma (OSCC), at the rate of $7.6 \%$, hence the mortality rate is also high [4]. Research reports state that OSCC originated from OSMF is clinically more invasive and also exhibits higher metastasis and recurrence rate than OSCC not originated from OSMF $[5,6]$.

The pathogenesis of the disease is thought to be multifactorial. Factors include habit of chewing areca nut, ingestion of chilies, genetic \& immunologic processes and nutritional deficiencies. In addition, to the above factors a possible autoimmune basis to the disease i.e. an association with specific human leukocyte antigen (HLA) has been proposed [7]. Of all these areca nut is one of the main etiological factors.

Progranulin (PGRN) also known as granulin-epithelin precursor, is a glycoprotein of 576 amino acids and pleiotropic in nature. It is known to play an important role in the maintenance and regulation of tissue development, embryogenesis, infectious diseases, inflammatory conditions, wound healing, and tumorigenesis [8]. It is basically a high 
Page 2 of 5

molecular weight secreted mitogen. It is abundantly expressed in rapidly cycling epithelial cells, in the immune system and in neurons, such as cerebellar Purkinje cells [8]. PGRN has been studied extensively in the context of rheumatoid arthritis which is mediated by TNF- $\alpha$ [9]. Various studies have also been done for the estimation of PGRN in several cancers and inflammatory diseases. The functions of progranulin are multifaceted; progranulin levels have yet been unexplored in the context of submucous fibrosis as well as oral cancer.

Enzyme linked immunosorbent assay (ELISA) is an established method used for estimating the levels of PGRN directly from the biological specimen (serum and saliva) with standard and rapid preparation of a specimen. Hence the present study aims to assess the serum and salivary levels of Progranulin in patients of oral submucous fibrosis and compare the same with normal control subjects.

\section{Objective}

The main objective of the present study was to analyse and compare the serum and salivary levels of progranulin in normal healthy controls and subjects with oral submucous fibrosis, also to see if there is any association with the levels of progranulin and disease progression of OSMF.

\section{Materials and Methods}

The study was conducted in the department of Oral pathology after approved by institutional ethical committee of SRM University (IRBNO: RMDC/IRB/2014/MDS/No.606). The study group consisted of 40 cases, Control (Group 1) 10 cases and oral submucous fibrosis (Group II) 30 cases (Table 1). Complete case histories, verbal \& written consent were obtained from all patients enrolled in the study (From Feb 2015 to July 2016).

\begin{tabular}{|l|l|l|}
\hline Study Group & $\begin{array}{l}\text { GROUP I } \\
(\mathbf{n}=10)\end{array}$ & $\begin{array}{l}\text { GROUP II } \\
(\mathbf{n}=\mathbf{3 0})\end{array}$ \\
\hline Age Range (in years) & $24-55$ & $20-56$ \\
\hline $\operatorname{Sex}(\mathrm{M} / \mathrm{F})$ & $9 / 1$ & $26 / 4$ \\
\hline
\end{tabular}

Table 1: Demographic details of study population.

\section{Inclusion and Exclusion criteria for samples}

\section{Group I}

Inclusion criteria

1. Age and sex matched individuals.

2. Patients from any geographical location.

\section{Exclusion criteria}

1. Presence of any underlying systemic illness.

2. Habits such as tobacco usage or alcohol.

3. Presence of oral inflammatory conditions such as gingivitis, periodontitis, and oral ulcers.

\section{Group II}

Inclusion criteria
1. Patients of any age and sex.

2. Patients from any geographical location.

3. Clinically diagnosed cases of Oral Submucous Fibrosis

(Classified based on clinical features of OSMF given by "PINDBORG in 1989")

\section{Exclusion criteria}

1. Presence of any underlying systemic illness.

2. Patients who are currently undergoing or having undergone any form of treatment for Oral Submucous Fibrosis.

3. Presence of oral inflammatory conditions such as gingivitis, periodontitis, and oral ulcers.

[Subjects with less than 20 natural teeth and with a diagnosis of chronic periodontitis based on clinical parameters like Probing Depth (PD), Clinical Attachment Level (CAL), Gingival Index (GI) were excluded.]

\section{Method of Sample Collection and Storage}

\section{Saliva}

Whole saliva was collected from patients in both groups. Each individual expectorated $5 \mathrm{ml}$ of saliva into a sterile centrifuge tube (between 9 a.m. and 11 a.m.). Following collection, the saliva was immediately centrifuged in a cooling centrifuge at $2500 \mathrm{rpm}$ for 15 minutes at $-4^{\circ} \mathrm{C}$. The resulting supernatant was separated into $1 \mathrm{ml}$ aliquots and stored at $-80^{\circ} \mathrm{C}$ freezer.

\section{Serum}

Blood was drawn from patients in both groups. $2 \mathrm{ml}$ of peripheral blood were drawn from subjects using standardized phlebotomy procedures and allowed to coagulate for $1 \mathrm{~h}$ at room temperature. Sera were separated by centrifugation in a cooling centrifuge at $1500 \mathrm{rpm}$ for $10 \mathrm{~m}$ at $-4^{\circ} \mathrm{C}$ and all specimens were immediately aliquoted and stored at $-80^{\circ} \mathrm{c}$ freezer.

No more than one freeze-thaw cycle was allowed for each sample. Further the collected samples were blinded and samples were subjected to Sandwich ELISA technique using Human PGRN (Progranulin) ELISA kit.

\section{Results}

The present study included a total of 40 subjects, out of which 10 were healthy controls and 30 were Oral Submucous Fibrosis (Table 2).

Group I: Comprised of normal healthy controls of which 9 were males and 1 was female with age range of 24-55 years.

Group II: Comprised of Oral submucous fibrosis of which 26 were male and 4 were female with age range of 20-56 years.

Statistical analysis of the data obtained was done using SPSS software version 22. The descriptive statistics such as mean and standard deviations (SD) were calculated for the individual groups. Comparison of PGRN levels between groups was done using $t$ test.Comparison of PGRN levels between different stages of OSMF was done using ANOVA followed by Tukey HSD Post Hoc Test. 


\begin{tabular}{|l|l|l|l|l|l|l|}
\hline Parameter & Group & $\mathbf{N}$ & $\begin{array}{l}\text { Mean } \\
\text { (ng/ml) }\end{array}$ & $\begin{array}{l}\text { Standard } \\
\text { Deviatio } \\
\mathbf{n}\end{array}$ & $\begin{array}{l}\text { P- } \\
\text { Value }\end{array}$ & $\begin{array}{l}\text { Level of } \\
\text { significance }\end{array}$ \\
\hline \multirow{2}{*}{ Saliva } & Control & 10 & 88.00 & 24.32 & $<$ & Significant at $95 \%$ \\
\cline { 2 - 7 } & OSMF & 30 & 160.20 & 76.36 & & \\
\hline \multirow{2}{*}{ Serum } & Control & 10 & 121.67 & 32.31 & $<001$ & Significant at $95 \%$ \\
\cline { 2 - 7 } & OSMF & 30 & 190.25 & 74.62 & & \\
\hline
\end{tabular}

Table 2: Comparison of PGRN levels between groups in serum and saliva.

Comparison of PGRN levels between groups was done using $t$ test ( $\mathrm{p}<0.05$ was considered to be statistically significant) (Table 3 and Table 4).

Comparison between salivary levels in control group and OSMF group revealed significance at 95\% CI (P value $<0.05)$.

Comparison between serum levels in control group and the OSMF group revealed significance at 95\% CI (P value $<0.05)$.

\begin{tabular}{|c|c|c|c|c|c|c|}
\hline Parameter & OSMF & $\mathbf{N}$ & $\begin{array}{l}\text { Mean } \\
(\mathrm{ng} / \mathrm{ml})\end{array}$ & $\begin{array}{l}\text { Standard } \\
\text { Deviation }\end{array}$ & $\begin{array}{l}\text { P. } \\
\text { Value }\end{array}$ & $\begin{array}{l}\text { Level of } \\
\text { significance }\end{array}$ \\
\hline \multirow{4}{*}{ Saliva } & Stage-I & 10 & 96.02 & 18.78 & \multirow{4}{*}{$<0.001$} & \multirow{4}{*}{$\begin{array}{l}\text { Significant } \\
\text { at } 95 \%\end{array}$} \\
\hline & Stage-II & 13 & 172.69 & 58.34 & & \\
\hline & Stage-III & 7 & 228.67 & 90.35 & & \\
\hline & Total & 30 & 160.20 & 76.35 & & \\
\hline \multirow{4}{*}{ Serum } & Stage-I & 10 & 116.59 & 28.43 & \multirow{4}{*}{$<0.001$} & \multirow{4}{*}{$\begin{array}{l}\text { Significant } \\
\text { at } 95 \%\end{array}$} \\
\hline & Stage-II & 13 & 210.34 & 54.79 & & \\
\hline & Stage-III & 7 & 258.17 & 66.30 & & \\
\hline & Total & 30 & 190.25 & 74.62 & & \\
\hline
\end{tabular}

Table 3: Comparison of PGRN values between OSMF stages.

\begin{tabular}{|l|l|l|l|l|}
\hline Parameter & \multicolumn{2}{|l|}{ OSMF STAGES } & \multicolumn{1}{l|}{$\begin{array}{l}\text { Mean } \\
\text { Difference }\end{array}$} & P-Value \\
\hline \multirow{3}{*}{ Progranulin Value-Saliva } & \multirow{2}{*}{ Stage-I } & Stage -II & -76.67 & 0.012 \\
\cline { 3 - 5 } & & Stage -III & -132.65 & $<0.001$ \\
\cline { 2 - 5 } & Stage -II & Stage -III & -55.98 & 0.123 \\
\hline Progranulin Value-Serum & Stage-I & Stage -II & -93.75 & $<0.001$ \\
\cline { 2 - 5 } & & Stage -III & -141.59 & $<0.001$ \\
\cline { 2 - 5 } & Stage -II & Stage -III & -47.83 & 0.129 \\
\hline
\end{tabular}

Table 4: Multiple Pair wise Comparison of PGRN levels between OSMF stages.

Comparison of PGRN levels within OSMF stages (GROUP II) was done using ANOVA followed by Tukey HSD Post Hoc Test

( $\mathrm{p}<0.05$ was considered to be statistically significant).
Comparison between salivary levels in OSMF group between each stage revealed significance at $95 \% \mathrm{CI}(\mathrm{P}$ value $<0.05)$.

Comparison between serum levels in OSMF group between each stage revealed significance at $95 \% \mathrm{CI}(\mathrm{P}$ value $<0.05)$.

\section{Discussion}

Progranulin is a multifunctional protein and its physiological function is complex. It is unclear whether the accumulation of PGRN represents an anti-inflammatory or proinflammatory mechanism. This dual role of PGRN is site specific. But whatever the role may be it has its implication in the inflammatory conditions [9].

In this study when serum PGRN levels were analyzed it was found to be increased in OSMF group $(190.25 \mathrm{ng} / \mathrm{ml})$ compared to the control group $(121.67 \mathrm{ng} / \mathrm{ml})$ and revealed significance at the level of $95 \%$ (Table 2). The results of the present study are in accordance with the previous studies dealt with various cancers. A study conducted by Cuevas Antonio et al. showed increase PGRN levels and he concluded in his studies that PGRN expression may be potentially involved in the pathogenesis and malignant progression of ovarian cancer [10]. Similarly Koo et al. in his study concluded that PGRN levels were clinically significant for predicting recurrence in patients with breast cancer [11].

Progranulin has emerged in the field of "Cubic of I", namely immunity, infection and inflammation. This multifaceted molecule has diverse functions pertaining to inflammation, although it's a major anti-inflammatory molecule its exact function varies depending on the stage and components of inflammation. In acute inflammation progranulin is important in the initiation of inflammation by the recruitment of fibroblasts and macrophages also at the same time it limits inflammation bycontrolling the production of pro-inflammatory cytokines. Progranulin has been studied extensively in the context of rheumatoid arthritis, a chronic inflammatory autoimmune disease which is mediated by TNF- $\alpha$.

An animal experiment carried out by Tang et al. showed that progranulin provides protection from inflammatory arthritis by blocking TNF- $\alpha$ [12]. Another investigation carried out by Tanaka et al. involved, PGRN analysis in patients with systemic lupus erythematosus and concluded it may be involved in pathogenesis by enhancing the TLR9 signalling and could be a useful biomarker for disease activity [13]. Qu et al. studied plasma PGRN concentrations in patients with Type 2 Diabetes and Obesity and found that PGRN concentrations were higher in Chinese patients with type 2 diabetes and obesity. In his study he also correlated PGRN levels closely with glycolipid metabolism, chronic inflammation and insulin resistance [14].

Studies using saliva as biological sample in PMOD and in oral cancer have increased greatly in the recent years however no studies have been done to evaluate the salivary PGRN levels in any PMOD or oral cancer. In the recent past PGRN was proved as a novel adipokine in periodontitis [15]. Priyanka et al. studied the crevicular fluid and serum concentrations of PGRN in chronic periodontitis and Type 2 Diabetes and found that it was increased in both these groups compared to control subjects [16]. Similar to this another study done by Ozcan et al. showed that the salivary progranulin levels were similar in healthy controls, gingivitis and periodontitis [17].

In our study similar to serum PGRN levels the mean salivary PGRN levels were also increased in OSMF group (160.20 ng/ml) compared to 
control group $(88 \mathrm{ng} / \mathrm{ml})$ and revealed significance at the level of $95 \%$ (Table 2).

The elevated serum and salivary levels of PGRN in patients with OSMF could be attributed to the fact that, OSMF is a chronic inflammatory condition and that during inflammation PGRN is cleaved by serine proteases into granulins which are proinflammatory. PGRN and processed granulin have opposite effects, PGRN prevents inflammation by blocking the TNF- $\alpha$ receptors and granulins have a pro inflammatory effect via neutralising the anti-inflammatory effect of progranulin [18].

PGRN has also been implicated in chronic inflammation, it acts by blocking TNF- $\alpha$ mediated signalling pathways by competing with TNF- $\alpha$ by binding to TNFr1/2 receptors, which was explained in the study by Yamamoto et al. 2014 where the serum and synovial PGRN levels were significantly increased in rheumatoid arthritis patients than patients with osteoarthritis [18]. It is known that TNF promotes an inflammatory response, and plays a vital role in pathogenesis of autoimmune disorders like rheumatoid arthritis and Crohn's disease. Due to these reasons, of late, the TNF inhibitor has been frequently used to treat such disorders. Interestingly, when PGRN was administered, it was found to bind with TNF and inhibit TNF signalling [19].

The role of TNF- $\alpha$ in the pathogenesis of oral submucous fibrosis is implicated both in regulation of inflammation as well as in the transcription of collagen and collagenase enzyme [6].

Additionally we also wanted to assess if there was a progressive increase in PGRN levels in different stages of OSMF. Despite the variations in the number of subjects in different stages of OSMF (i.e. Stage $I=10$, Stage $I I=13$ and Stage $I I I=7$ ) the salivary as well as the serum PGRN levels showed to elevate as the stage of the disease advances. And it showed to be statistically significant (Table 3 and Table 4). It is a well-known fact that the mediators of inflammation play a role in the pathogenesis of OSMF. Amongst the various mediators, TNF- $\alpha$ plays a pivotal role as it causes decrease in collagenase enzyme activity and increase in collagen production with progression of the disease [20]. Hence this could be the reason for increasing trends in PGRN levels at various stages of OSMF.

In the current study the mean serum PGRN levels seemed to be higher than the salivary PGRN levels which could be because PGRN is reported to have a complex interaction with inflammation, far beyond its known inhibitory effects. In the inflammatory process, it seems to be divided into small peptides called granulin, which in turn has a proinflammatory effect. The released granulins also neutralize the antiinflammatory property of progranulin. Therefore, whether PGRN will have an anti-inflammatory or a pro-inflammatory effect is determined by the target tissue. So the spiking of serum PGRN levels compared to that of salivary PGRN levels would be because it is a multifunctional protein.

\section{Conclusion}

Hence it can be inferred that this multifaceted molecule, progranulin has an important role to play in the pathogenesis of OSMF. However, the role of progranulin in pathogenesis of OSMF can be ascertained by doing this study in more number of samples along with clinical or histological grading of different stages of OSMF.

\section{Recommendation}

Future directions to better theorise the role of progranulin in pathogenesis of OSMF would be by analysing other parameters like the correlation of progranulin levels with TNF and soluble TNF receptor, and the ratio of PGRN/TNF in relation to the stage of the disease can be studied, as progranulin mainly acts by blocking TNF- $\alpha$ mediated signalling pathways by competing with TNF- $\alpha$ by binding to TNFr $1 / 2$ receptors, which would also help to target this molecule in the therapeutic aspect as well.

\section{References}

1. Tilakaratne WM, Klinikowski MF, Saku T, Peters TJ, Warnakulasuriya S (2006) Oral submucous fibrosis: review on aetiology and pathogenesis. Oral Oncology 42: 561-568.

2. Ajit Auluck M, Rosin MP, Lewei Zhang B, Sumanth K (2008) Oral submucous fibrosis, a clinically benign but potentially malignant disease: report of 3 cases and review of the literature. J Can Dent Assoc 74: 735-740.

3. Reddy V, Wanjari PV, Banda NR, Reddy P (2011) Oral submucous fibrosis: correlation of clinical grading to various habit factors. Int J Dent Clin 3: 21-24.

4. Dyavanagoudar SN (2009) Oral submucous fibrosis: Review on etiopathogenesis. J Cancer Sci Ther 1: 72-77.

5. Chaturvedi P, Vaishampayan SS, Nair S, Nair D, Agarwal JP, et al. (2013) Oral squamous cell carcinoma arising in background of oral submucous fibrosis: a clinicopathologically distinct disease. Head Neck 35: 1404-1409.

6. Ekanayaka RP, Tilakaratne WM (2013) Oral submucous fibrosis: Review on mechanisms of pathogenesis and malignant transformation. J Carcinogene Mutagene 122: 192-199.

7. Rajalalitha P, Vali S (2005) Molecular pathogenesis of oral submucous fibrosis-a collagen metabolic disorder. J Oral Pathol Med 34: 321-328.

8. Ong $\mathrm{CH}$, Bateman A (2003) Progranulin (granulin-epithelin precursor PC-cell derived growth factor, acrogranin) in proliferation and tumorigenesis. Histol Histopathol 18:1275-1288.

9. Liu CJ (2011) Progranulin: a promising therapeutic target for rheumatoid arthritis. FEBS lett 585: 3675-3680.

10. Cuevas Antonio R, Cancino C, Arechavaleta Velasco F, Andrade A, Barron L, et al. (2010) Expression of progranulin (Acrogranin/PCDGF/ Granulin-Epithelin Precursor) in benign and malignant ovarian tumors and activation of MAPK signaling in ovarian cancer cell line. Cancer invest 28: 452-458.

11. Koo DH, Park CY, Lee ES, Ro J, Oh SW (2012) Progranulin as a prognostic biomarker for breast cancer recurrence in patients who had hormone receptor-positive tumors: a cohort study. PLoS ONE 7: e39880.

12. Tang W, Lu Y, Tian QY, Zhang Y, Guo FJ, et al. (2011) The growth factor progranulin binds to TNF receptors and is therapeutic against inflammatory arthritis in mice. Science 332: 478-484.

13. Tanaka A, Tsukamoto H, Mitoma H, Kiyohara C, Ueda N, et al. (2012) Serum progranulin levels are elevated in patients with systemic lupus erythematosus, reflecting disease activity. Arthritis Res Ther 14: R244.

14. Qu H, Deng H, Hu Z (2013) Plasma progranulin concentrations are increased in patients with type 2 diabetes and obesity and correlated with insulin resistance. Mediators Inflamm 2013: 360190.

15. Matsubara T, Mita A, Minami K, Hosooka T, Kitazawa S, et al. (2012) PGRN is a key adipokine mediating high fat diet-induced insulin resistance and obesity through IL-6 in adipose tissue. Cell Metab 15: 38-50.

16. Priyanka N, Kumari M, Kalra N, Arjun P, Naik SB, et al. (2013) Crevicular fluid and serum concentrations of progranulin and high sensitivity CRP in chronic periodontitis and type 2 diabetes. Dis Markers 35: 389-394. 
Citation: Swarnalakshmi R, Ramya R, Priyadharshini N, Preethi L, Rajashree P, et al. (2018) Assessment of Serum and Salivary Progranulin Levels in Oral Submucous Fibrosis. J Carcinog Mutagen 9: 311. doi:10.4172/2157-2518.1000311

Page 5 of 5

17. Özcan E, Saygun NI, Serdar MA, Kurt N (2015) Evaluation of the salivary levels of visfatin, chemerin, and progranulin in periodontal inflammation. Clin Oral Investig 19: 921-928.

18. Yamamoto Y, Takemura M, Serrero G, Hayashi J, Yue B, et al. (2014) Increased serum GP88 (progranulin) concentrations in rheumatoid arthritis. Inflammation 37: 1806-1813.
19. Wang BC, Liu H, Talwar A, Jian J (2015) New discovery rarely runs smooth: an update on progranulin/TNFR interactions. Protein Cell 6: 792-803.

20. Wojdasiewicz P, Poniatowski ŁA, Szukiewicz D (2016) The role of inflammatory and anti-inflammatory cytokines in the pathogenesis of osteoarthritis. Mediators Inflamm 2014: 19 